\title{
Nomogram predictive model of post-operative recurrence in non-functioning pituitary adenoma
}

\author{
Wen Lyu ${ }^{1,2}$, Xu Fei ${ }^{1,2}$, Cheng Chen ${ }^{1,2}$, Yuqun Tang ${ }^{3}$ \\ ${ }^{1}$ Department of Neurosurgery, Shenzhen People's Hospital, Second Clinical Medical College of Jinan University, Shenzhen, China; ${ }^{2}$ Department of \\ Neurosurgery, First Affiliated Hospital of Southern University of Science and Technology, Shenzhen, China; ${ }^{3}$ Department of Oncology, 74th Army \\ Hospital of PLA, Guangzhou, China \\ Contributions: (I) Conception and design: W Lyu; (II) Administrative support: W Lyu; (III) Provision of study materials or patients: W Lyu, X Fei; (IV) \\ Collection and assembly of data: W Lyu, C Chen; (V) Data analysis and interpretation: W Lyu, Y Tang; (VI) Manuscript writing: All authors; (VII) \\ Final approval of manuscript: All authors. \\ Correspondence to: Wen Lyu. Department of Neurosurgery, Shenzhen People's Hospital, Second Clinical Medical College of Jinan University, \\ Shenzhen 518020, China; Department of Neurosurgery, First Affiliated Hospital of Southern University of Science and Technology, Shenzhen \\ 518020, China. Email: 13828787488@139.com.
}

Backgrounds To analyze and predict the possibility of post-operative recurrence in non-functioning pituitary adenoma (NFPA) patients, we investigated the clinical factors leading to tumor recurrence and built a nomogram predictive model based on these risk factors.

Methods: A single-center retrospective study was performed. A total of 145 NFPA patients who underwent surgical treatment at Shenzhen People's Hospital from September 2013 to January 2019 were selected. Among them, 52 patients were diagnosed with recurrence of NFPA according to follow-up investigations. Binary logistic regression analysis was used to determine the significant risk factors. A nomogram model was then built to predict recurrence using these factors.

Results: The univariate analysis and the binary logistic regression analysis showed that age, tumor size, cavernous invasion, sphenoid sinus invasion, and surgical extension were significant factors affecting tumor recurrence. We then built a nomogram model to predict post-operative recurrence in NFPA patients using these factors. The correlation analysis indicated that sphenoid sinus invasion [hazard ratio $(\mathrm{HR})=13.14,95 \%$ confidence interval (CI): 7.03-24.58, $\mathrm{P}<0.0001$ ], cavernous sinus invasion (HR =7.53, 95\% CI: 4.27-13.28, $\mathrm{P}<0.0001)$, and tumor size ( $\mathrm{HR}=11.06,95 \% \mathrm{CI}: 6.11-20.03, \mathrm{P}<0.0001)$ could promote the recurrence of NFPA. In contrast, advanced age $(\mathrm{HR}=0.50,95 \% \mathrm{CI}: 0.28-0.86, \mathrm{P}<0.0001)$ and gross total resection $(\mathrm{HR}$ $=0.12,95 \%$ CI: $0.07-0.22, \mathrm{P}<0.0001)$ could effectively inhibit recurrence.

Conclusions: In this study, we developed a nomogram predictive model based on the significant recurrence-associated factors for NFPA. This nomogram may aid neurosurgeons in the post-operative prediction of recurrence, and may facilitate tailored counseling of individual patients.

Keywords: Non-functioning pituitary adenoma (NFPA); recurrence; nomogram

Submitted Dec 03, 2020. Accepted for publication Feb 03, 2021.

doi: $10.21037 / g s-21-47$

View this article at: http://dx.doi.org/10.21037/gs-21-47

\section{Introduction}

Non-functioning pituitary adenomas (NFPAs) represent more than one-third of pituitary neuroendocrine tumors (PitNETs), which are benign and slow-glowing. Nonetheless, NFPAs may lead to complications of tumor mass effects, and $57 \%$ exhibit invasive potential (1). Patients with NFPA are usually treated with operative therapy, especially transsphenoidal surgery (TSS). However, several studies have shown that the post-operative recurrence rates range from $35 \%$ to $73 \%$ (2-5). Because of hormonal 
inactivity, NFPA are usually diagnosed until the occurrence of headache, visual field defects, causing by compression of macroadenomas, which resulting in the peripheral invasion, incomplete excision, and high possibility of tumor recurrence $(6,7)$. The factors that predict post-surgery recurrence of NFPA remain to be elucidated. NFPA are not associated with any clinical hormonal syndrome, which challenged for the early tumor diagnosis (8). Besides, NFPA constitute nearly one third of pituitary adenomas, so it is necessary to explore the independent predictive factors for tumor recurrence of NFPA.

In previous studies, genetic markers and clinical factors have shown potential predictive value for recurrence (1,9-12). Chiloiro et al. suggested that a Ki-67 cut off value of $1.5 \%$ was helpful for devising clinical follow-up plans (13). Another study indicated that a Ki-67 labeling index (LI) above $2.2 \%$ should attract more attention and require shorter intervals of follow-up with early adjuvant therapy and magnetic resonance imaging (MRI) scans (14). In contrast, Yao et al. showed no statistical significance of the Ki-67 LI in primary $(n=20)$ or recurrent tumors $(n=15)(15)$. Recently, Cheng et al. demonstrated a predictive model for NFPA that could facilitate prognostic evaluation and guide early interventions (9). In addition, the modified Knosp classification and the new World Health Organization (WHO) 2017 histopathological classification have contributed to an enhanced understanding of prognosis and predictive markers $(12,16)$.

Efforts have been made to assess the association between clinical variables and recurrence (17). However, attempts to predict post-surgical recurrence by comprehensively incorporating multiple variables have rarely been made, especially in NFPA. A nomogram is a model that predicts the probability of a particular outcome by summing the scores of each risk factor. Nomograms can depict outcome as a continuous probability, and can also graphically demonstrate the combined effect of each variable. Previous study has tried to build a nomogram model with noninvasive radiomics approach to distinguish NFPA subtypes of null cell adenomas and other subtypes (18). However, few studies focused on the prediction of tumor recurrence by using nomogram predictive model. In our present study, we developed a nomogram by combining clinical variables and clinical images to predict the post-operative recurrence of NFPA. We present the following article in accordance with the TRIPOD reporting checklist (available at http://dx.doi. org/10.21037/gs-21-47).

\section{Methods}

\section{Patient selection}

This was a single-center retrospective study. A total of 145 patients with histologically confirmed NFPA who underwent surgical resection at our institution from September 2013 to January 2019 were enrolled, including 98 men and 47 women. Their age ranged from 26 to 82 years (mean, 57 years), with a median follow-up of 43 months (range, 36-100 months). Among them, 52 patients were diagnosed with recurrence of NFPA. Patients treated with chemotherapy or radiotherapy, or with a follow-up less than 3 years after surgical resection, were excluded.

The initial pathological diagnosis was based on the cytological appearance of the tumor tissue with immunohistochemistry. Histological subtypes were defined according to the WHO 2017 classification of neuroendocrine tumors. There was no discrepancy between clinical data and pathological diagnosis. Tumors were classified into gonadotroph $(\mathrm{n}=53)$, null-cell $(\mathrm{n}=31)$, corticotroph $(n=29)$, thyrotroph $(n=14)$, and plurihomonal Pit-1-positive ( $\mathrm{n}=18)$ subtypes.

For all cases, tumor resection was performed with TSS, and cavernous sinus invasion and sphenoid sinus invasion status was determined according to the MR images and operating records, where the performing neurosurgeons documented their impressions. Surgery extension meant total resection or partial resection of tumors. Tumor size, cavernous sinus invasion, sphenoid sinus invasion, visual defects, and surgical extensions are described in detail in Table 1. The time of progression-free survival (PFS) of NFPA patients was measured from TSS to tumor recurrence, and was evaluated for further analysis. The study was conducted in accordance with the Declaration of Helsinki (as revised in 2013). This study was approved by the Ethics Committee of Shenzhen People's Hospital (No. LL-KY-2021005). Informed consent was obtained from all individual participants included in the study.

\section{Construction of the nomogram}

The nomogram and calibration plots were generated using the "rms" R package (version 3.4.3). The predictive accuracy of this nomogram was estimated by a concordance index, which showed the consistency between the actual and predicted outcome. A calibration plot was used to visualize the predictive accuracy of the nomogram. The model- 
Table 1 Basic clinical data of patients with non-functioning pituitary adenoma (NFPA)

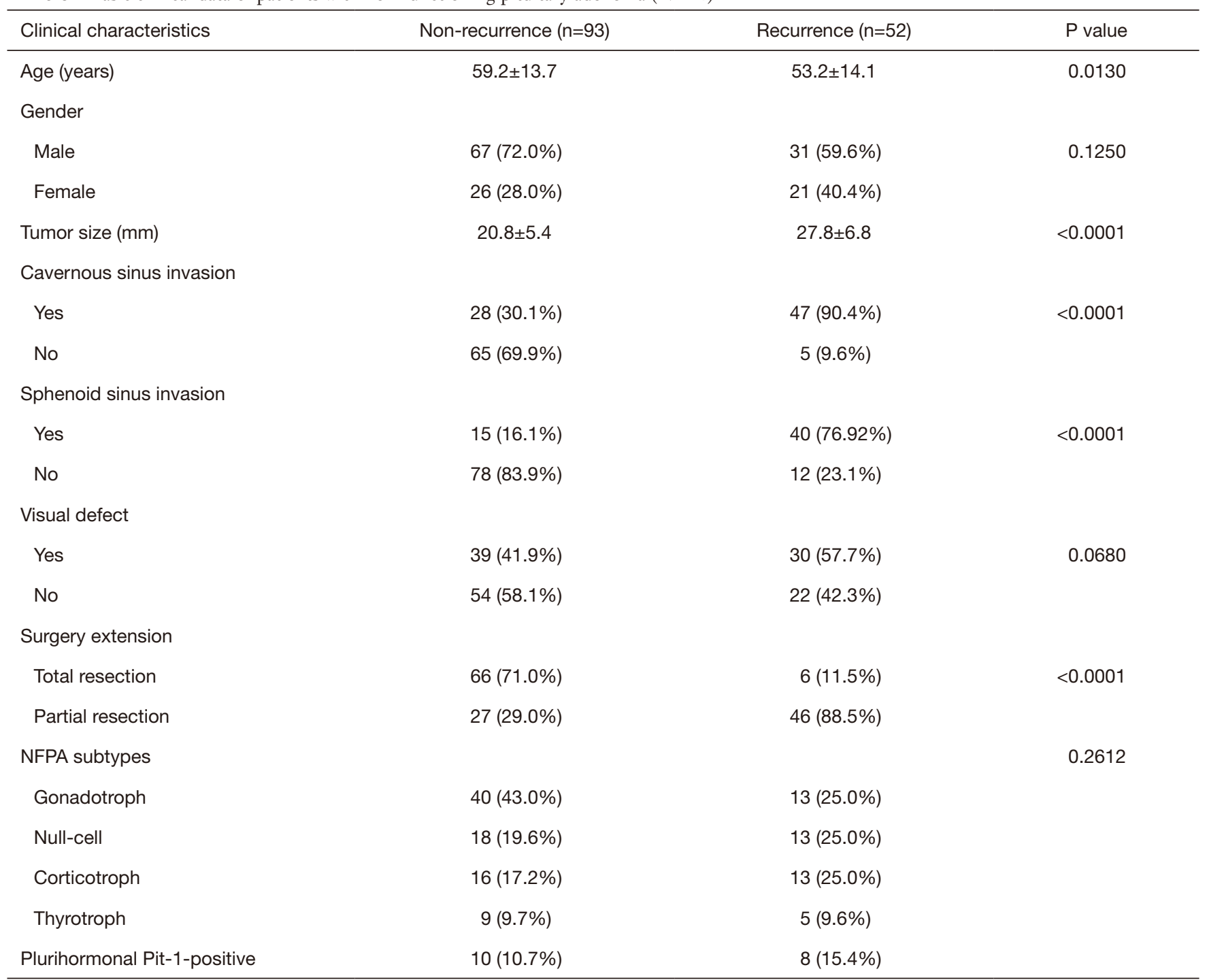

predicted recurrence and actual outcome were plotted on the $\mathrm{x}$-axis and $\mathrm{y}$-axis, respectively, and the $45^{\circ}$ line represented the best prediction.

\section{Statistical analysis}

Data analysis was performed using the commercially available SPSS 22.0 statistical software (IBM Corp., Armonk, NY, USA). Count data are expressed as mean \pm standard deviation (SD), and categorical data are expressed as a percentage. According to the clinical characteristics, the following 7 variables were included in this study: gender, age, tumor size, cavernous invasion, sphenoid sinus invasion, visual defects, and surgical extension. $\mathrm{P}$ values, odds ratios (OR) and $95 \%$ confidence intervals (CIs) were used to describe all risk factors of recurrence in this study. The $\chi^{2}$ and Student's $t$-test were performed in the univariate analysis to initially assess the relationship between the aforementioned predictors and recurrence. Subsequently, factors with $\mathrm{P}<0.05$ were included in the binary logistic regression analysis, which was used to analyze the association between these factors and the risk of recurrence. Correlations between the quantitative variables were verified by Spearman's correlation test. The KaplanMeier method was used to estimate PFS. A P value $<0.05$ was considered statistically significant. 


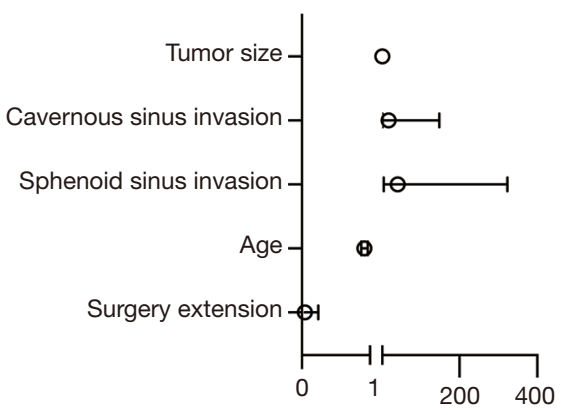

$\begin{array}{ccc}\text { OR } & 95 \% \mathrm{Cl} & \mathrm{P} \text { value } \\ 1.217 & 1.064-1.393 & 0.004 \\ 17.813 & 2.147-147.763 & 0.008 \\ 41.004 & 5.196-323.588 & 0.0001 \\ 0.918 & 0.871-0.967 & 0.001 \\ 0.044 & 0.005-0.397 & 0.005\end{array}$

Figure 1 Basic clinical date of patients with non-functioning pituitary adenoma (NFPA).

\section{Results}

\section{Clinical characteristics of the progression-free and recurrence groups}

The baseline characteristics of all 145 participants are summarized in Table 1. The progression-free group included 67 male patients and 26 female patients, with an average age of $59.3 \pm 13.7$ years old and an average tumor size of $20.8 \pm 5.4 \mathrm{~mm}$. The recurrence group had 31 males and 21 females at $53.2 \pm 14.1$ years old and an average tumor size of $27.8 \pm 6.8 \mathrm{~mm}$, respectively. Comparisons between the progression-free group and the recurrence group suggested that age, tumor size, cavernous sinus invasion, sphenoid sinus invasion, and surgical extension were potential recurrenceassociated factors, while gender, visual defects, and NFPA subtypes showed no statistical significance (Table 1).

\section{Analysis of risk factors for the recurrence of NFPA}

After binary logistic regression analysis, it was confirmed that age $(\mathrm{P}=0.001 ; \mathrm{OR}=0.918 ; 95 \% \mathrm{CI}: 0.871-0.967)$, tumor size $(\mathrm{P}=0.004$; OR $=1.217$; $95 \% \mathrm{CI}$ : 1.064-1.393), cavernous sinus invasion $(\mathrm{P}=0.008$; $\mathrm{OR}=17.813 ; 95 \% \mathrm{CI}$ : 2.147-147.763), sphenoid sinus invasion ( $\mathrm{P}=0.0001$; OR $=41.004 ; 95 \%$ CI: $5.196-323.588)$, and surgical extension $(\mathrm{P}=0.005$; OR $=0.044 ; 95 \% \mathrm{CI}: 0.005-0.397)$ were the significant risk factors contributing to the recurrence of NFPA after TSS. The ORs and $95 \%$ CIs of the above factors are shown in a forest plot in Figure 1.

\section{Construction of the nomogram based on clinical risk factors}

To develop a practical method for clinicians to predict the possibility of NFPA recurrence, we constructed a nomogram model, which integrated the factors of age, tumor size, cavernous sinus invasion, sphenoid sinus invasion, and surgical extension (Figure $2 A$ ). To generate the nomogram, the value attributed to an individual patient was located on each axis, and the top line was used to determine the total points for each variable value. Then a line was drawn downward to the survival axis to determine the risk of recurrence. As shown in Figure 2B, the line-segment in the calibration plot was close to the line, which indicated that the nomogram model performed well in the calibration plots. Receiver operating characteristic (ROC) analysis showed that the area under the ROC curve (AUC) of this nomogram model was 0.953 (Figure 2C).

\section{PFS analysis}

After we constructed this predictive model, we could effectively predict the possibility of NFPA recurrence. We wanted to further analyze the correlation between risk factors and PFS. Therefore, the PFS underlying different risk factors were shown in the correlation analysis and Kaplan-Meier curves.

The correlation analysis indicated that sphenoid sinus invasion [hazard ratio $(\mathrm{HR})=13.14,95 \%$ CI: 7.03-24.58, $\mathrm{P}<0.0001$ ], cavernous sinus invasion $(\mathrm{HR}=7.53,95 \% \mathrm{CI}$ : 4.27-13.28, $\mathrm{P}<0.0001$ ), and tumor size (HR $=11.06,95 \%$ CI: $6.11-20.03, \mathrm{P}<0.0001)$ could promote the recurrence of NFPA. In contrast, advanced age (HR $=0.50,95 \%$ CI: 0.28-0.86, $\mathrm{P}=0.0127$ ) and gross total resection (GTR; HR $=0.12,95 \%$ CI: $0.07-0.22, \mathrm{P}<0.0001)$ could effectively inhibit recurrence (Figure 3).

\section{Discussion}

In this study, we generated a clinical nomogram based on 
A

Points

Age

Tumor diameter

Cavernous invasion

Sphenoid invasion

Surgery extension

Total Points

Risk of recurrence

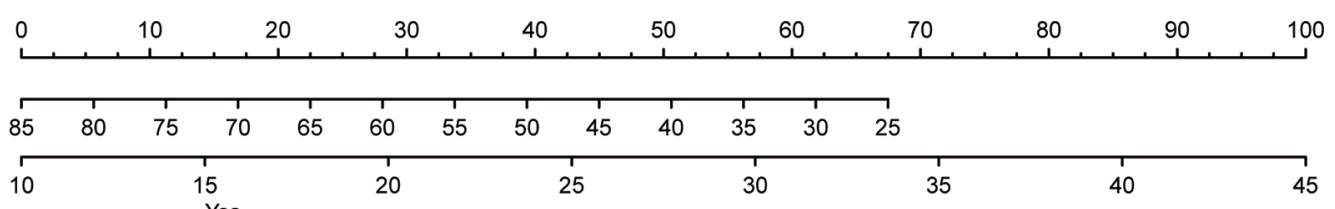
Yes

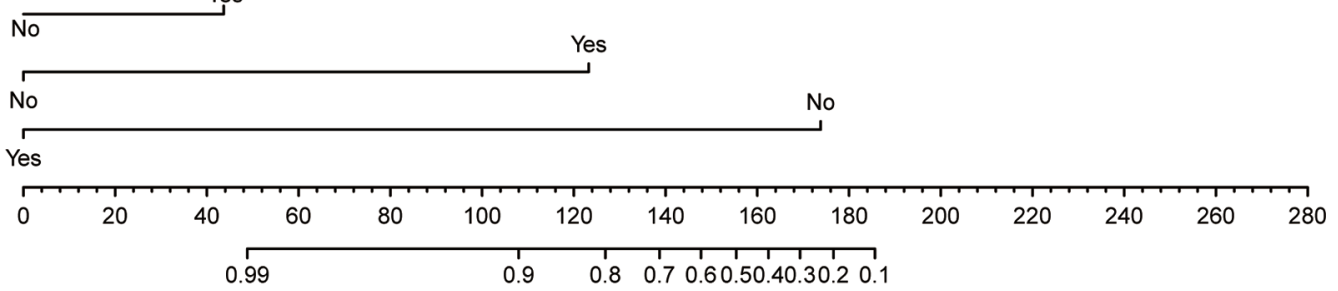

B

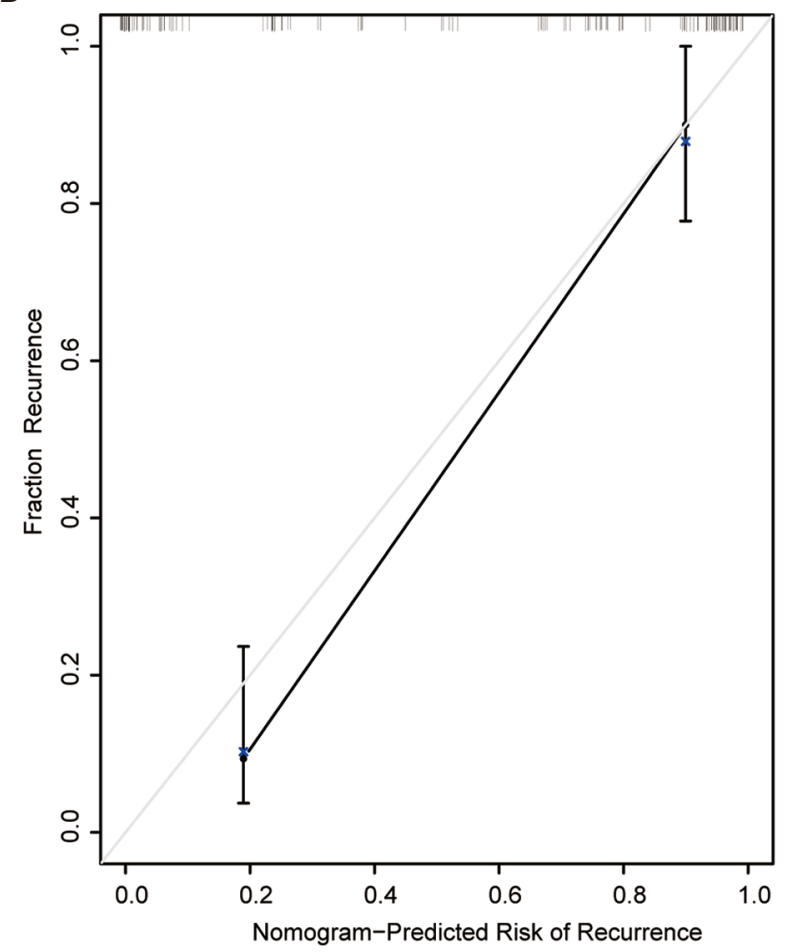

C

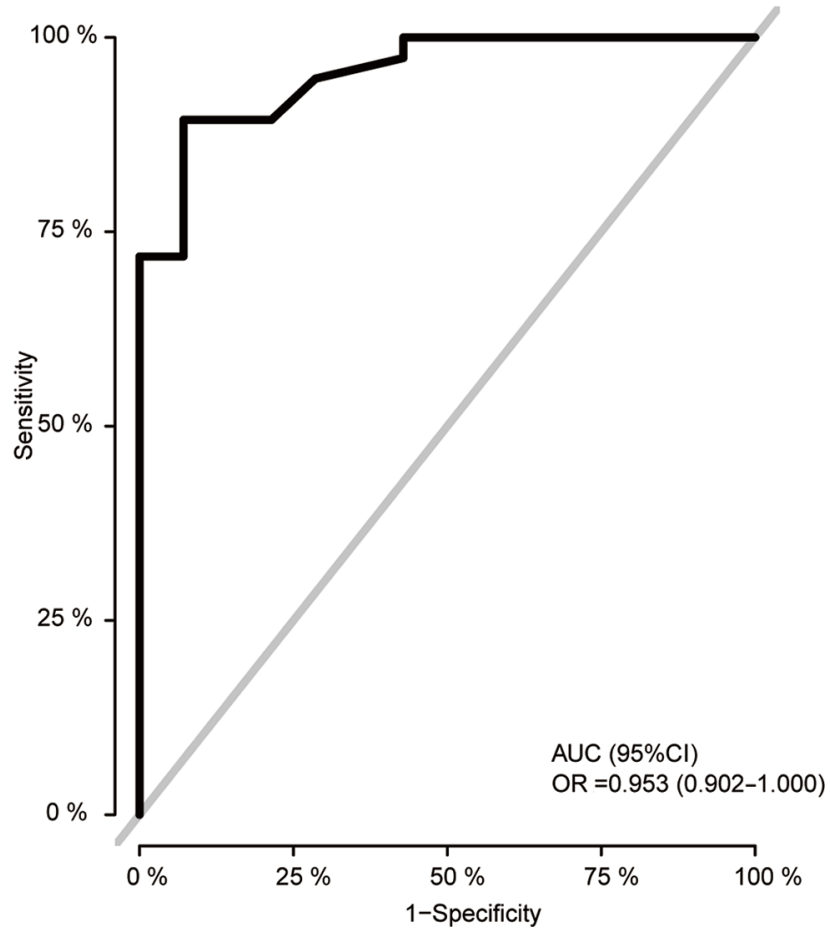

Figure 2 Nomogram for the prediction of non-functioning pituitary adenoma (NFPA) recurrence. (A) The nomogram included the significant risk factors. (B) A calibration curve was generated to predict the possibility of recurrence. (C) Receiver operating characteristic curve analysis was performed to estimate the accuracy of the nomogram.

age, tumor size, cavernous sinus invasion, sphenoid sinus invasion, and surgery extension for the individualized evaluation of the post-operative recurrence of NFPA. Incorporating these risk factors, the nomogram built by $\mathrm{R}$ language outperformed the single signatures in the whole sets. The final nomogram had an AUC of 0.953 and was well calibrated. Neurosurgeons can therefore use this nomogram in clinical practice to offer more accurate predictions of recurrence after surgery for patients with NFPA.

NFPA has been treated with a low probability of recurrence, however, some patients are not diagnosed until the recurrent tumor is large enough to cause mass effects. Previous studies have indicated that clinical factors such as age, gender, tumor size, and tumor invasion have no significant predictive value for recurrence, while many 

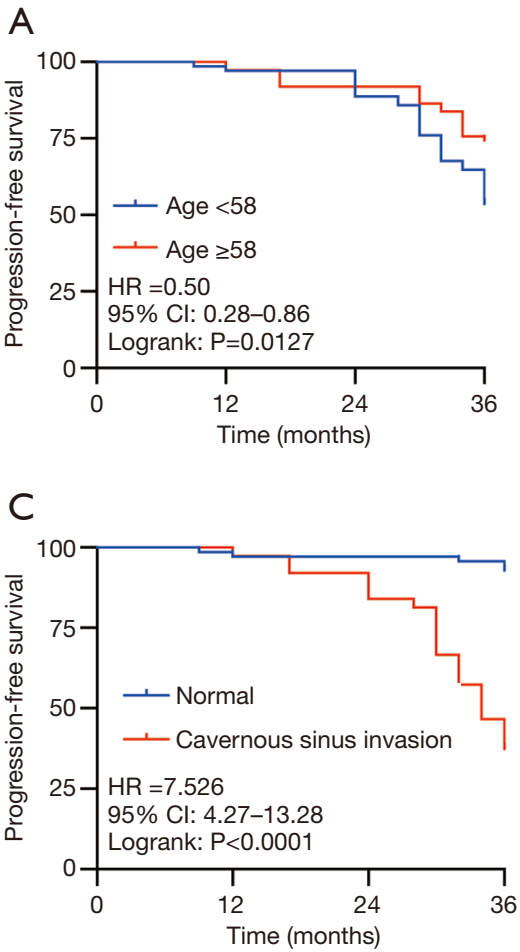
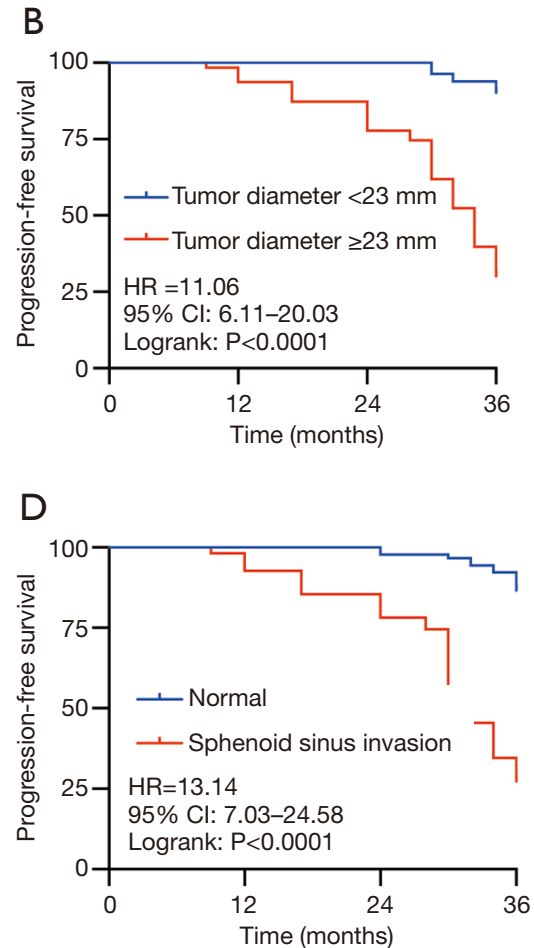

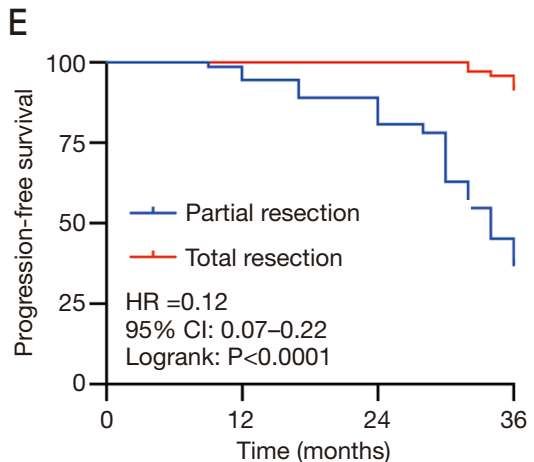

Figure 3 Progression-free survival analysis with risk factors. Kaplan-Meier curves showing the progression-free survival rates in nonfunctioning pituitary adenoma (NFPA) patients, with risk factors including age (A), tumor diameter (B), cavernous sinus invasion (C), sphenoid sinus invasion (D), and surgical extension (E).

other factors that influence the proliferation of pituitary adenomas, such as angiogenesis, growth factors, oncogenes, apoptosis, tumor suppressor genes, and hormone receptors, have been shown to be predictive factors $(15,19-21)$. In this study, our results indicated that age, tumor size, cavernous sinus invasion, sphenoid sinus invasion, and surgery extension were the significant risk factors that were used to build the nomogram.

The role of age in recurrence is controversial. Yao et al. and Batista $e t a l$. both revealed that age was not associated with recurrence $(22,23)$. However, Losa et al. indicated that younger age was associated with the possibility of tumor recurrence (24). In addition, age has shown a statistically significant relationship with Ki-67 expression (25).

According to the direction of tumor invasion, invasive pituitary adenomas can be divided into sphenoid sinus invasion and cavernous sinus invasion. Few studies have investigated the differences between these 2 types in terms of their influence on recurrence. Cavernous sinus invasion can act as a prognostic variable for the long-term control of NFPAs (26). The rate of GTR negatively correlated with tumor grades, while rates were only $30.0 \%$ for grade 3B, which was classified according to the modified Knosp classification (12). Our data suggests that sphenoid sinus invasion may be a nonnegligible risk factor. Recently, a meta-analysis demonstrated that endoscopic TSS (eTSS) led to a higher rate of GTR compared to microscopic TSS for pituitary adenoma patients (27). Ferreli et al. undertook a retrospective review and revealed that eTSS resulted in $87.5 \%$ recurrence-free survival, with a mean followup of 61 months (range, 36-166 months) (28). Moreover, Zhang et al. showed that high-field intraoperative magnetic resonance imaging (iMRI) increased the GTR rate in endoscopic TSS for NFPAs. They also indicated that tumor size, cavernous sinus invasion, and surgical history were important predictors of GTR in patients with NFPA (29). Furthermore, O'Sullivan $e t$ al. revealed that all patients with total resection did not show recurrence during follow-up (2).

The risk factors for recurrence have been discussed, including clinical factors, surgical techniques, genetic markers, and predictive models. However, few studies have focused on the PFS of NFPA. Lee et al. showed that the 
PFS of NFPA was $60 \%$ at 10 years (30). Guo et al. built a two-circRNA signature and demonstrated its predictive value for tumor recurrence, and found that it was especially correlated with the PFS of NFPA patients (31). On the other hand, Zhu et al. indicated that bone-invasive pituitary adenomas (BIPA) had worse PFS than non-BIPAs NFPA subtypes (32). Furthermore, iMRI improved GTR rates, which correlated with longer PFS (29). Moreover, some dopamine agonists have shown to be effective for treating residual NFPA, and reduced the recurrence of NFPA (33-35). These data suggest that it is of great importance to find strategies to predict recurrence. Although MRI scans and $\mathrm{Ki}-67$ both are routine tests in clinical diagnosis and therapy, selecting proper scan sequence and getting in-depth information are also challenges for clinical neurosurgery. So we emphasizing the clinical variables, which contained valuable predictive information and can be timely observed. Combination of clinical various and experience of neurosurgery made this predictive model more practical. Previous study showed that executive function was significantly associated with age at treatment, and that young patients exhibited a better outcome after definitive treatment (36). However, few studies focused on the predictive value of age in tumor recurrence prediction. We added the factor of age in our nomogram model and performed with high accuracy. Our study demonstrated that the clinical factors sphenoid sinus invasion, cavernous sinus invasion, and tumor size could promote the recurrence of NFPA. In contrast, advanced age and GTR could effectively inhibit recurrence.

This study still has several limitations. Firstly, the singlecenter study design is one of the most significant limitations, and selection bias might also have influenced the results. Therefore, a multi-center validation study is required for further analysis. Secondly, the present nomogram is based on a small number of cases which might have limited its predictive power. In spite of these limitations, this nomogram can help predict the recurrence of NFPA with good accuracy. Lastly, outcome was measured at the last follow-up. It would therefore be better if we controlled the same timepoint for all patients. Future studies investigating the combination of more clinical factors and several omics approaches would provide further insights into the diagnosis and follow-up treatment for NFPA.

In conclusion, this study focused on the prediction of post-operative NFPA recurrence by developing a nomogram using significant clinical risk factors. The nomogram performed better than one single factor, and may therefore aid in the follow-up and long-term management of NFPA.

\section{Conclusions}

Our novel predictive nomogram model may aid neurosurgeons in the post-operative prediction of recurrence, and may also facilitate tailored counseling for individual patients.

\section{Acknowledgments}

Funding: None.

\section{Footnote}

Reporting Checklist: The authors have completed the TRIPOD reporting checklist. Available at http://dx.doi. org/10.21037/gs-21-47

Data Sharing Statement: Available at http://dx.doi. org/10.21037/gs-21-47

Conflicts of Interest: All authors have completed the ICMJE uniform disclosure form (available at http://dx.doi. org/10.21037/gs-21-47). The authors have no conflicts of interest to declare.

Ethical Statement: The authors are accountable for all aspects of the work in ensuring that questions related to the accuracy or integrity of any part of the work are appropriately investigated and resolved. The study was conducted in accordance with the Declaration of Helsinki (as revised in 2013). This study was approved by the Ethics Committee of Shenzhen People's Hospital (No. LLKY-2021005). Informed consent was obtained from all individual participants included in the study. This article does not contain any studies with animals performed by any of the authors.

Open Access Statement: This is an Open Access article distributed in accordance with the Creative Commons Attribution-NonCommercial-NoDerivs 4.0 International License (CC BY-NC-ND 4.0), which permits the noncommercial replication and distribution of the article with the strict proviso that no changes or edits are made and the original work is properly cited (including links to both the formal publication through the relevant DOI and the license). See: https://creativecommons.org/licenses/by-nc-nd/4.0/. 


\section{References}

1. Lelotte J, Mourin A, Fomekong E, et al. Both invasiveness and proliferation criteria predict recurrence of nonfunctioning pituitary macroadenomas after surgery: a retrospective analysis of a monocentric cohort of 120 patients. Eur J Endocrinol 2018;178:237-46.

2. O'Sullivan EP, Woods C, Glynn N, et al. The natural history of surgically treated but radiotherapy-naive nonfunctioning pituitary adenomas. Clin Endocrinol (Oxf) 2009;71:709-14.

3. Reddy R, Cudlip S, Byrne JV, et al. Can we ever stop imaging in surgically treated and radiotherapy-naive patients with non-functioning pituitary adenoma? Eur J Endocrinol 2011;165:739-44.

4. Zhang X, Horwitz GA, Heaney AP, et al. Pituitary tumor transforming gene (PTTG) expression in pituitary adenomas. J Clin Endocrinol Metab 1999;84:761-7.

5. Woollons AC, Hunn MK, Rajapakse YR, et al. Nonfunctioning pituitary adenomas: indications for postoperative radiotherapy. Clin Endocrinol (Oxf) 2000;53:713-7.

6. Penn DL, Burke WT, Laws ER. Management of nonfunctioning pituitary adenomas: surgery. Pituitary 2018;21:145-53.

7. Chanson P, Raverot G, Castinetti F, et al. Management of clinically non-functioning pituitary adenoma. Ann Endocrinol (Paris) 2015;76:239-47.

8. Asa SL, Ezzat S. The pathogenesis of pituitary tumors. Annu Rev Pathol 2009;4:97-126.

9. Cheng $\mathrm{S}, \mathrm{Wu} \mathrm{J}, \mathrm{Li} \mathrm{C}$, et al. Predicting the regrowth of clinically non-functioning pituitary adenoma with a statistical model. J Transl Med 2019;17:164.

10. Guo J, Wang Z, Miao Y, et al. A twocircRNA signature predicts tumour recurrence in clinical nonfunctioning pituitary adenoma. Oncol Rep 2019;41:113-24.

11. Wang X, Zhang D, Ma S, et al. Predicting the likelihood of early recurrence based on mRNA sequencing of pituitary adenomas. Gland Surg 2019;8:648-56.

12. Buchy M, Lapras V, Rabilloud M, et al. Predicting early post-operative remission in pituitary adenomas: evaluation of the modified knosp classification. Pituitary 2019;22:467-75.

13. Chiloiro S, Bianchi A, Doglietto F, et al. Radically resected pituitary adenomas: prognostic role of Ki 67 labeling index in a monocentric retrospective series and literature review. Pituitary 2014;17:267-76.

14. Steno A, Bocko J, Rychly B, et al. Nonfunctioning pituitary adenomas: association of Ki-67 and HMGA-1 labeling indices with residual tumor growth. Acta Neurochir (Wien) 2014;156:451-61; discussion 461.

15. Yao X, Gao H, Li C, et al. Analysis of Ki67, HMGA1, $\mathrm{MDM} 2$, and RB expression in nonfunctioning pituitary adenomas. J Neurooncol 2017;132:199-206.

16. Manojlovic-Gacic E, Engstrom BE, Casar-Borota O. Histopathological classification of non-functioning pituitary neuroendocrine tumors. Pituitary 2018;21:119-29.

17. Wass JA, Reddy R, Karavitaki N. The postoperative monitoring of nonfunctioning pituitary adenomas. Nat Rev Endocrinol 2011;7:431-4.

18. Zhang S, Song G, Zang Y, et al. Non-invasive radiomics approach potentially predicts non-functioning pituitary adenomas subtypes before surgery. Eur Radiol 2018;28:3692-701.

19. Noh TW, Jeong HJ, Lee MK, et al. Predicting recurrence of nonfunctioning pituitary adenomas. J Clin Endocrinol Metab 2009;94:4406-13.

20. Saeger W. Pituitary tumors: prognostic indicators. Endocrine 2005;28:57-66.

21. Farrell WE, Clayton RN. Molecular pathogenesis of pituitary tumors. Front Neuroendocrinol 2000;21:174-98.

22. Yao X, Zhang Y, Wu L, et al. Immunohistochemical Study of NR2C2, BTG2, TBX19, and CDK2 Expression in 31 Paired Primary/Recurrent Nonfunctioning Pituitary Adenomas. Int J Endocrinol 2019;2019:5731639.

23. Batista RL, Trarbach EB, Marques MD, et al. Nonfunctioning Pituitary Adenoma Recurrence and Its Relationship with Sex, Size, and Hormonal Immunohistochemical Profile. World Neurosurg 2018;120:e241-6.

24. Losa M, Mortini P, Barzaghi R, et al. Early results of surgery in patients with nonfunctioning pituitary adenoma and analysis of the risk of tumor recurrence. J Neurosurg 2008;108:525-32.

25. Trott G, Ongaratti BR, de Oliveira Silva CB, et al. PTTG overexpression in non-functioning pituitary adenomas: Correlation with invasiveness, female gender and younger age. Ann Diagn Pathol 2019;41:83-9.

26. Chang EF, Zada G, Kim S, et al. Long-term recurrence and mortality after surgery and adjuvant radiotherapy for nonfunctional pituitary adenomas. J Neurosurg 2008;108:736-45.

27. Almutairi RD, Muskens IS, Cote DJ, et al. Gross total resection of pituitary adenomas after endoscopic vs. microscopic transsphenoidal surgery: a meta-analysis. Acta Neurochir (Wien) 2018;160:1005-21. 
28. Ferreli F, Turri-Zanoni M, Canevari FR, et al. Endoscopic endonasal management of non-functioning pituitary adenomas with cavernous sinus invasion: a 10- year experience. Rhinology 2015;53:308-16.

29. Zhang Z, Yang K, Xia Y, et al. High-Field Intraoperative Magnetic Resonance Imaging Increases Extent of Resection and Progression-Free Survival for Nonfunctioning Pituitary Adenomas. World Neurosurg 2019;127:e925-31.

30. Lee MH, Lee JH, Seol HJ, et al. Clinical Concerns about Recurrence of Non-Functioning Pituitary Adenoma. Brain Tumor Res Treat 2016;4:1-7.

31. Guo J, Wang Z, Miao Y, et al. A two-circRNA signature predicts tumour recurrence in clinical non-functioning pituitary adenoma. Oncol Rep 2019;41:113-24.

32. Zhu H, Guo J, Shen Y, et al. Functions and Mechanisms of Tumor Necrosis Factor-alpha and Noncoding RNAs in Bone-Invasive Pituitary Adenomas. Clin Cancer Res

Cite this article as: Lyu W, Fei X, Chen C, Tang Y. Nomogram predictive model of post-operative recurrence in non-functioning pituitary adenoma. Gland Surg 2021;10(2):807-815. doi: 10.21037/gs-21-47
2018;24:5757-66.

33. Lin S, Zhang A, Zhang X, et al. Treatment of Pituitary and Other Tumours with Cabergoline: New Mechanisms and Potential Broader Applications. Neuroendocrinology 2020;110:477-88.

34. Batista RL, Musolino NRC, Cescato VAS, et al. Cabergoline in the Management of Residual Nonfunctioning Pituitary Adenoma: A Single-Center, Open-Label, 2-Year Randomized Clinical Trial. Am J Clin Oncol 2019;42:221-7.

35. Greenman Y, Cooper O, Yaish I, et al. Treatment of clinically nonfunctioning pituitary adenomas with dopamine agonists. Eur J Endocrinol 2016;175:63-72.

36. Müssig K, Leyhe T, Besemer B, et al. Younger age is a good predictor of better executive function after surgery for pituitary adenoma in adults. J Int Neuropsychol Soc 2009;15:803-6. 